\title{
Perbandingan Kadar Vitamin C Pada Nanas Segar dan Keripik Nanas Dengan Metode Spektrofotometri UV-Vis
}

\author{
Azlaini Yus Nasution', Dini Mardhiyani1, Kony Putriani' ${ }^{1}$, Dhea Ananda², Virgiawan \\ Saputro1 \\ 1Prodi S1 Farmasi, FKIK, Universitas Abdurrab \\ 2D III Analis Farmasi dan Makanan, FKIK, Universitas Abdurrab \\ Jl. Riau Ujung No. 73 Pekanbaru, Indonesia \\ azlaini.yus@univrab.ac.id
}

\begin{abstract}
Pineapple is one of the fruit that contains vitamin C. Vitamin $C$ is a complex compound that is needed by the body which serves to help regulate or metabolize the body. In Kualu village, Kampar, pineapple is processed into pineapple chips. The purpose of this study was to determine the ratio of vitamin C levels in fresh pineapple and pineapple chips using the UVVis spectrophotometry method with a wavelength of $265 \mathrm{~nm}$. The result of this research is a linear regression equation was obtained which was $y=0,0809 x-0,1239$. From the regression, the average level of fresh pineapple is 4,274 ppm and pineapple chips get an average level of 2,760 ppm.
\end{abstract}

Keyword : spectrophotometry UV-Vis, pineapple, pineapple chips, vitamin C

Abstrak Nanas merupakan salah satu buah yang mengandung vitamin C. Vitamin C merupakan senyawa kompleks yang sangat dibutuhkan oleh tubuh yang berfungsi untuk membantu pengaturan atau proses metabolisme tubuh. Di Desa Kualu Nanas, Kampar, nanas diolah menjadi keripik nanas. Tujuan dari penelitian ini adalah untuk mengetahui perbandingan kadar vitamin $C$ yang ada pada nanas segar dan keripik nanas dengan menggunakan spketrofotometri Uv-Vis dengan panjang gelombang $265 \mathrm{~nm}$. Hasil penelitian ini adalah pada uji linearitas didapatkan persamaan regresi linear yaitu y = 0,0809x - 0,1239. Dari persamaan regresi tersebut didapatkan kadar rata-rata nanas segar yaitu 4,274 ppm dan keripik nanas mendapatkan kadar rata-rata yaitu 2,760 ppm.

Kata kunci : Spektrofotometri UV-Vis, nanas, keripik nanas, vitamin C

\section{Pendahuluan}

Vitamin merupakan senyawa kompleks yang sangat dibutuhkan oleh tubuh yang berfungsi untuk membantu pengaturan atau proses metabolisme tubuh. Salah satu vitamin yang diperlukan oleh tubuh adalah vitamin C (Irianto, 2013). Vitamin C atau asam askorbat adalah salah satu vitamin yang terbuat dari turunan heksosa yang larut dalam air dan mudah rusak karena pemanasan. Disamping itu, vitamin C memiliki gugus kromofor yang peka terhadap rangsangan cahaya. Salah satu tanaman yang mengandung vitamin C adalah nanas (Badriyah dan Manggara, 2015).

Nanas adalah salah satu jenis buah yang banyak diminati oleh masyarakat. Dalam keadaan segar buah nanas tidak bisa tahan lama, hanya bisa bertahan selama tujuh hari pada kondisi kamar (suhu $28-30^{\circ} \mathrm{C}$ ). Sifat buah demikian akan menjadikan kendala dalam penyediaan buah, untuk komsumsi segar atau penyimpanan untuk stok pengolahan selanjutnya. Saat ini, buah nanas telah diolah menjadi berbagai macam produk pangan olahan (Bartholemew, Paull, dan Rohrbarch, 2003). Buah nanas yang mengalami proses pengolahan dapat meningkatkan daya simpan dan jangkuan pemasarannya lebih luas. Hal ini dapat menjadi nilai tambah pendapatan petani nanas. Buah nanas dapat diolah menjadi berbagai macam produk 
seperti, selai nanas, manisan buah, dodol, sirup, jeli dan keripik nanas. Hal ini merupakan salah-satu upaya agar buah nanas tidak terbuang percuma dan membusuk saat panen raya (Afrianti, 2010; Suyanti, 2010).

Desa Kualu Nanas merupakan desa penghasil nanas di Kabupaten Kampar. Nanas telah diolah menjadi berbagai jenis pangan olahan diantaranya dibuat keripik (Magribi, Suasti, dan Wilis, 2017). Keripik nanas adalah keripik hasil olahan nanas segar yang digoreng dengan cara khusus, biasanya menggunakan mesin penggoreng hampa udara yang disebut dengan mesin vaccum frying (Silitonga, Salmiah, dan Ayu, 2018). Proses pengolahan nanas menjadi keripik melewati proses pencucian dan penggorengan dengan waktu yang lama. Hal itu menjadi penyebab vitamin C pada keripik nanas mengalami penurun kadar, karena sifat vitamin C yang mudah larut di dalam air dan rusak karena pemanasan (Putri dan Setiawati, 2015).

Ada beberapa metode yang dikembangkan untuk menentukan kadar vitamin C, salah satu yang digunakan yaitu spektrofotometri UV-Vis. Metode spektrofotometri UV-Vis dapat memberikan informasi baik analisis kualitatif maupun kuantitatif. Analisis kualitatif digunakan untuk mengidentifikasi kualitas obat atau metabolitnya. Sedang untuk analisis kuantitatif dapat memperoleh data berupa panjang gelombang maksimum, intensitas, efek pH dan pelarut (Harmita, 2014).

Menurut penelitian yang telah dilakukan oleh Putri dan Setiawati (2015), kadar vitamin C pada nanas segar sebesar 4,274 ppm, sehingga penulis tertarik melakukan penelitian terkait denagn perbandingan kadar vitamin C pada nanas segar dan keripik nanas dengan metode spektrofotometri UV-Vis.

\section{Metode Penelitian}

\subsection{Alat dan Bahan}

Alat yang digunakan dalam penelitian ini adalah spketrofotometer UV-Vis, timbangan analitik, corong, labu ukur, pipet volume, beaker glass, dan gelas ukur. Bahan yang digunakan adalah nanas segar, keripik nanas, baku pembanding vitamin $\mathrm{C}$ dan aquadest.

\subsection{Prosedur Kerja}

\subsubsection{Pembuatan Larutan Baku Vitamin C}

Konsentrasi larutan baku vitamin C yang dibuat adalah 100 ppm.

\subsubsection{Pembuatan Larutan Kurva Kalibrasi}

Dipipet larutan baku vitamin C 100 ppm ke dalam labu ukur $100 \mathrm{~mL}$ yang telah dibungkus dengan aluminium foil masing-masing sebesar $5 \mathrm{~mL}, 6 \mathrm{~mL}, 7 \mathrm{~mL}, 8 \mathrm{~mL}$, dan $9 \mathrm{~mL}$. Kemudian ditambahkan aquadest hingga tanda batas lalu homogenkan hingga didapatkan konsentrasi 5 ppm, 6 ppm, 7 ppm, 8 ppm, dan 9 ppm.

\subsubsection{Penetapan Panjang Gelombang Maksimum Larutan Vitamin C}

Diambil larutan konsentrasi 7 ppm dan kurva kalibrasi lalu dimasukkan ke dalam kuvet, selanjutnya di scanning pada panjang gelombang 200-400 nm dengan blanko aquadest.

\subsubsection{Pengukuran Larutan Kurva Kalibrasi}

Diukur absorbansi masing-masing larutan kurva kalibrasi 4 ppm, 5 ppm, 6 ppm, 7 ppm, 8 ppm, dan 9 ppm pada panjang gelombang maksimum yang diperoleh. 


\subsubsection{Penentuan Kadar Sampel}

a. Nanas

Nanas segar dipotong kecil-kecil lalu dihaluskan dengan lumpang. Kemudian ditimbang sebanyak 5 gram dan dilarutkan dengan aquadest dalam labu ukur $100 \mathrm{~mL}$. Lalu disaring, hasil pernyaringan dipipet sebanyak $5 \mathrm{~mL}$ dan diencerkan hingga $100 \mathrm{~mL}$, diukur absorbansinya menggunakan spektrofotometer UV-Vis pada panjang gelombang maksimum.

b. Keripik Nanas

Keripik nanas dipotong kecil-kecil lalu dihaluskan dengan lumpang. Kemudian ditimbang 5 gram, dilarutkan dengan aquadest dalam labu ukur $100 \mathrm{~mL}$. Dilakukan penyaringan, lalu dipipet sebanyak $5 \mathrm{~mL}$ dan diencerkan hingga $100 \mathrm{~mL}$, diukur absorbansinya menggunakan spektrofotometer UV-Vis pada panjang gelombang maksimum.

\subsubsection{Analisis Data}

Analisis data menggunakan persamaan garis regresi linear $\mathrm{y}=\mathrm{bx}+\mathrm{a}$, yang diperoleh dari pengukuran kurva kalibrasi. Persamaan ini selanjutnya digunakan untuk menghitung kadar vitamin C dalam sampel.

\section{Hasil dan Pembahasan}

Penelitian ini dilakukan untuk menentukan perbandingan kadar vitamin C pada nanas segar dan keripik nanas dengan metode spektrofotometri UV-Vis. Spektrofometri UV-Vis adalah metode analisis untuk pengukuran konsentrasi suatu senyawa berdasarkan kemampuan senyawa tersebut mengabsorbsi berkas sinar atau cahaya. Vitamin C dapat di ukur dengan menggunakan spektrofotometer pada rentang 200-400 nm karena vitamin C memiliki gugus kromofor yang dapat menyerap sinar UV (Karinda et al.,2013).

Panjang gelombang $(\lambda)$ maksimum vitamin $C$ yang diperoleh yaitu $265 \mathrm{~nm}$ dengan nilai serapan 0,290, kurva pengukuran panjang gelombang maksimum vitamin C dapat dilihat pada Gambar 1 . Penentuan panjang gelombang maksimum dilakukan terlebih dahulu pada penelitian ini. Panjang gelombang maksimum adalah panjang gelombang dimana suatu zat memberikan penyerapan paling tinggi. Tujuan penentuan panjang gelombang maksimum pada penelitian ini yaitu pada panjang gelombang kepekaannya juga maksimum karena pada panjang gelombang maksimum tersebut, perubahan absorbansi untuk setiap satuan konsentrasi adalah yang paling besar; di sekitar panjang gelombang maksimum, bentuk kurva absorbansi datar dan pada kondisi tersebut hukum Lambeer-Beer akan terpenuhi; jika dilakukan pengukuran ulang maka kesalahan yang disebabkan oleh pemasangan ulang panjang gelombang akan kecil sekali (Gandjar dan Abdul, 2012).

Putri dan Setiawati (2015), menyatakan bahwa pada 7 ppm didapatkan nilai absorbansi tertinggi pada panjang gelombang maksimum $270 \mathrm{~nm}$, sedangkan pada penelitian yang didapatkan panjang gelombang maksimum $265 \mathrm{~nm}$. Panjang gelombang maksimum ini mengalami pergerseran hipsokromik 
(pergeseran biru) yaitu pergeseran panjang gelombang maksimum ke arah panjang gelombang yang lebih pendek. Hal tersebut mungkin dikarenakan kematangan pada nanas segar berbeda.

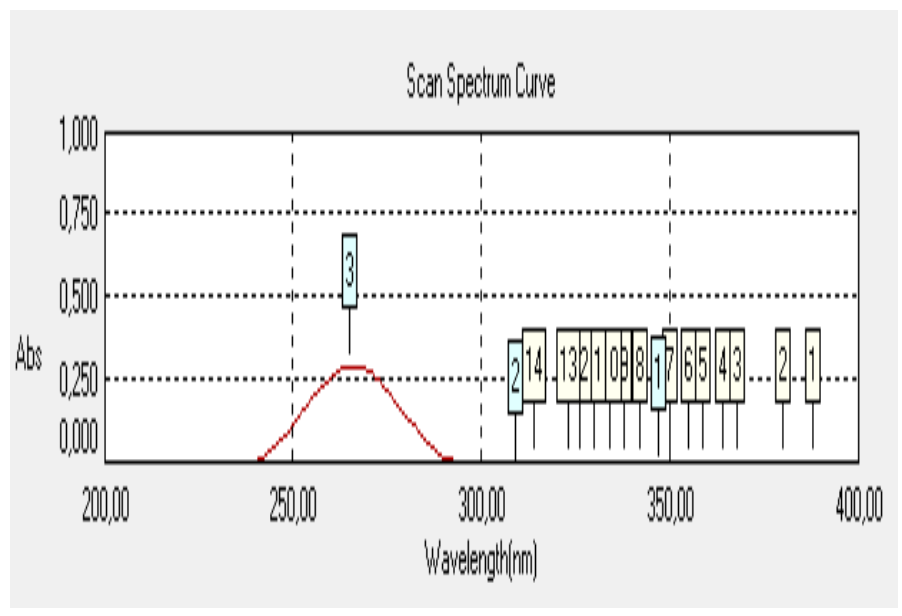

Keterangan:

3 = panjang gelombang maksimum vitamin C

Gambar 1. Kurva Panjang Gelombang Maksimum

Panjang gelombang maksimum juga dapat digunakan untuk menentukan kurva kalibrasi. Kurva kalibrasi adalah grafik yang menghubungkan antara konsentrasi (x) dan absorbansi (y) sehingga membentuk garis linear. Persamaan regresi linear yang didapatkan yaitu $y=0,0809 x-0,1239$ dengan koefisien (r) sebesar 0,9977. Hasil kurva kalibrasi dapat dilihat pada Gambar 2. Kriteria penerimaan dari koefisien korelasi $(r)$ sebesar $r>0,99$ menunjukkan linearitas yang sangat baik. Nilai maksimum dari koefisien korelasi (r) adalah 1, yang menunjukkan adanya korelasi yang tepat antara konsentrasi dengan absorbansi (Lestari et al., 2011). Hal ini berarti semakin koefisien korelasi (r) mendekati 1 atau sama dengan 1, maka semakin baik linearitasnya.

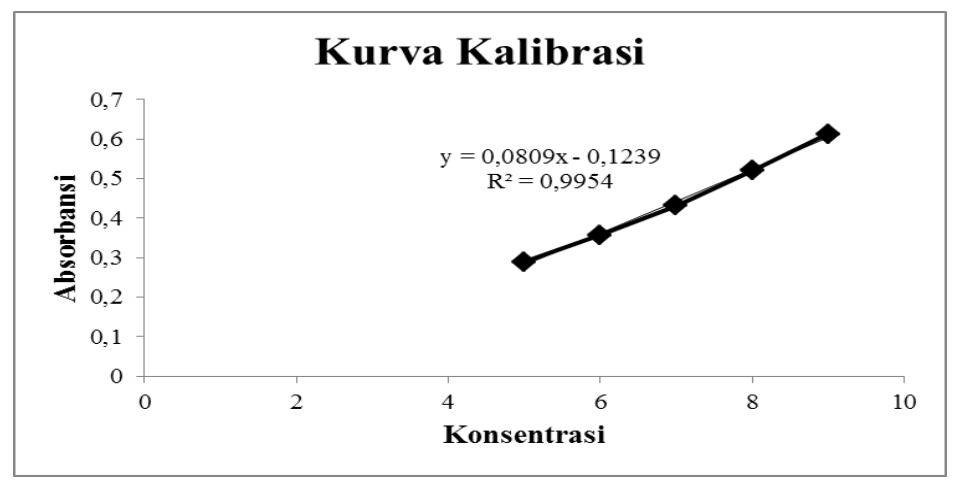

Gambar 2. Kurva kalibrasi vitamin C 
Sebelum penelitian, dilakukan preparasi sampel dengan cara dihaluskan. Kemudian sampel tersebut dilarutkan menggunakan aquadest, lalu disaring menggunakan kertas saring. Tujuan digunakannya aquadest karena vitamin C mudah larut dalam air (Departemen Kesehatan Republik Indonesia, 2014) dan tujuan penyaringan tersebut agar zat yang tidak terlarut dalam sampel tersaring semua sehingga tidak menganggu saat pengukuran sampel.

Kadar vitamin $\mathrm{C}$ yang terkandung di dalam nanas segar dengan 5 kali pengulangan secara berturutturut dalam ppm adalah 4,409; 4,353; 4,23; 4,165 dan 4,211 dengan kadar rata-rata 4,274 ppm. Kadar vitamin C yang terkandung di dalam keripik nanas dengan 5 kali pengulangan secara berturut turut dalam ppm adalah 2,904; 2,763; 2,813; 2,902 dan 2,421 dengan kadar rata- rata 2,761 ppm

Menurut Putri dan Setiawati (2015), kadar vitamin C yang didapatkan pada nanas segar sebesar 3,4274 ppm, sedangkan dari hasil penelitian didapatkan rata-rata kadar vitamin C pada nanas segar sebesar 4,274 ppm. Pada sampel keripik nanas didapatkan rata-rata kadar vitamin C sebesar 2,761 ppm. Perbedaan kadar vitamin C nanas segar dan keripik nanas ini terjadi karena adanya peningkatan suhu saat proses pengolahan nanas menjadi keripik nanas dan vitamin C mudah teroksidasi oleh pemanasan.

\section{Kesimpulan}

Berdasarkan penelitian yang telah dilakukan diperoleh kesimpulan bahwa kadar vitamin C pada nanas segar lebih tinggi yaitu 4,274 ppm dibandingkan kadar vitamin C pada keripik nanas yaitu $2,761 \mathrm{ppm}$.

\section{Referensi}

Afrianti, L. H. 2010. 33 Macam Buah-buahan Untuk Kesehatan. Bandung: C.V Alfabeta

Badriyah, L., dan A. B Manggara. 2015. Penetapan Kadar Vitamin C Pada Cabai Merah (Capsicum annum L.) Menggunakan Metode Spektrofotometri UV-VIS. Jurnal Wiyata, Volume 2 (1): 26

Bartholemew, D. P., R. E. Paull, dan K. G. Rohrbarch. 2003. The Pineapple, Production, and Uses. United Kingdom: CABI Publishing

Departemen Kesehatan Republik Indonesia. 2014. Farmakope Indonesia Edisi V. Jakarta

Gandjar, I. G., dan A. Rohman. 2012. Analisa Obat Secara Spektroskopi dan Kromatografi. Yogyakarta: Pustaka Pelajar

Harmita. 2014. Analisa Fitokimia, potensiometri dan Spektroskopi. Jakarta: EGC

Irianto, K. 2013. Solusi Sehat Peranan Vitamin dan Mineral Bagi Kesehatan. Bandung: Yrama Media

Karinda, M., Fatimawali, dan G. Citraningtyas. 2013. Perbandingan Hasil Penetapan Kadar Vitamin C Mangga Dodol Dengan Menggunakan Metode Spektrofotometri UV-Vis dan Iodometri. Jurnal Ilmiah Farmasi-UNSRAT, Volume 2 (1): 86-89

Magribi. R. A., Y. Suasti, dan R. Wilis. 2017. Multiplier Effect Pertanian Nanas (Ananas comosus) Terhadap 
JOPS (Journal Of Pharmacy and Science)

Vol 3 No 1 Desember 2019

Penyerapan Tenaga Kerja Dan Pendapatan Masyarakat Di Desa Kualu Nanas, Kecamatan Tambang, Kabupaten Kampar, Provinsi Riau. Jurnal Buana, Volume 1 (1): 90

Putri, M. P., dan Y. H. Setiawati. 2015. Analisa Kadar Vitamin C Pada Nanas Segar (Ananas comosus L.) dan Buah Naga Kaleng Dengan Metode Spektrofotometri UV-Vis. Jurnal Ilmiah, volume 2 (1): 35-36

Silitonga, H. V., Salmiah, dan S. F. Ayu. 2018. Analisis Nilai Tambah Pengelohan Nanas Menjadi Keripik dan Sirup. Jurnal USU, Volume 9 (4): 3-6

Suyanti. 2010. Panduan Mengolah 2 Jenis Buah. Surabaya: PT Niaga Swadaya. 